\title{
Strategies to Prevent Catheter-Associated Urinary Tract Infections in Acute Care Hospitals: 2014 Update
}

\author{
Evelyn Lo, MD; ;,a Lindsay E. Nicolle, MD; ${ }^{2, a}$ Susan E. Coffin, MD, MPH; ${ }^{3}$ Carolyn Gould, MD, MS; \\ Lisa L. Maragakis, MD, MPH; Jennifer Meddings, MD, MSc; ${ }^{5}$ David A. Pegues, MD; ${ }^{7}$ \\ Ann Marie Pettis, RN, BSN, CIC; ${ }^{8}$ Sanjay Saint, MD, MPH; ${ }^{9}$ \\ Deborah S. Yokoe, MD, MPH ${ }^{10}$
}

\section{P UR POSE}

Previously published guidelines are available that provide comprehensive recommendations for detecting and preventing healthcare-associated infections (HAIs). The intent of this document is to highlight practical recommendations in a concise format designed to assist acute care hospitals in implementing and prioritizing their catheter-associated urinary tract infection (CAUTI) prevention efforts. This document updates "Strategies to Prevent Catheter-Associated Urinary Tract Infections in Acute Care Hospitals," published in 2008. This expert guidance document is sponsored by the Society for Healthcare Epidemiology of America (SHEA) and is the product of a collaborative effort led by SHEA, the Infectious Diseases Society of America (IDSA), the American Hospital Association (AHA), the Association for Professionals in Infection Control and Epidemiology (APIC), and The Joint Commission, with major contributions from representatives of a number of organizations and societies with content expertise. The list of endorsing and supporting organizations is presented in the introduction to the 2014 updates. $^{2}$

\section{SECTION 1: RATIONALE AND STATEMENTS}

\section{OF CONCERN}

\section{Burden of CAUTIs}

A. Urinary tract infection (UTI) is one of the most common hospital-acquired infections; $70 \%-80 \%$ of these infections are attributable to an indwelling urethral catheter. ${ }^{3,4}$ The burden of CAUTI in pediatric patients is not well defined.
B. Twelve to sixteen percent of adult hospital inpatients will have a urinary catheter at some time during admission. ${ }^{5}$

C. The daily risk of acquisition of bacteriuria varies from $3 \%$ to $7 \%$ when an indwelling urethral catheter remains in situ.

D. Morbidity attributable to any single episode of catheterization is limited, ${ }^{6}$ but the high frequency of catheter use in hospitalized patients means the cumulative burden of CAUTI is substantial. , $^{3,7,8}$

II. Outcomes associated with CAUTI

A. Infection is the most important adverse outcome of urinary catheter use. ${ }^{7,9}$ The CAUTI rates reported in 2011 for facilities reporting to the National Healthcare Safety Network (NHSN) were $0.2-4.8$ per 1,000 catheter-days for adult inpatient units and 0-1.6 per 1,000 days for pediatric units. ${ }^{9}$ At one Veterans Affairs hospital, $0.3 \%$ of catheter-days involved symptomatic UTI. ${ }^{10}$

B. In 2011 , CAUTI rates from intensive care units (ICUs) that reported to NHSN ranged from 1.2 to 4.5 per 1,000 urinary catheter-days in adult ICUs and from 1.4 to 3.1 per 1,000 urinary catheter-days in pediatric ICUs. ${ }^{9}$ Symptomatic UTIs in adult ICUs voluntarily reporting to NHSN declined from 1990 to 2007, with a range of an $18.6 \%$ decline in cardiothoracic units to a $67 \%$ decline in medical-surgical ICUs. ${ }^{7}$ A $7 \%$ reduction was observed nationally in CAUTI incidence reported between 2009 and 2011, with modest reductions in incidence reported from ward locations but no changes in incidence reported from ICUs. ${ }^{11}$

C. During a 3-year period, 61 Quebec hospitals reported that $21 \%$ of all bloodstream infections (BSIs) identified

Affiliations: 1. St. Boniface General Hospital and University of Manitoba, Winnipeg, Manitoba, Canada; 2. Health Sciences Centre and University of Manitoba, Winnipeg, Manitoba, Canada; 3. Children's Hospital of Philadelphia, Philadelphia, Pennsylvania; 4. Centers for Disease Control and Prevention, Atlanta, Georgia; 5. Johns Hopkins University School of Medicine, Baltimore, Maryland; 6. Department of Internal Medicine, University of Michigan Medical School, Ann Arbor, Michigan; 7. Hospital of the University of Pennsylvania and Perelman School of Medicine, University of Pennsylvania, Philadelphia, Pennsylvania; 8. University of Rochester Medical Center, Rochester, New York; 9. Ann Arbor Veterans Affairs Medical Center and the University of Michigan, Ann Arbor, Michigan; 10. Brigham and Women's Hospital and Harvard Medical School, Boston, Massachusetts; a. These authors contributed equally to this work.

Received January 16, 2014; accepted January 16, 2014; electronically published April 7, 2014.

Infect Control Hosp Epidemiol 2014;35(5):464-479

(C) 2014 by The Society for Healthcare Epidemiology of America. All rights reserved. 0899-823X/2014/3505-0003\$15.00. DOI: 10.1086/675718 
48 hours or more after admission were from a urinary source and that $71 \%$ of these were device associated. The incidence was 1.4 urinary BSIs per 10,000 patient-days. All-cause 30 -day mortality in these patients was $15 \% .^{12}$

D. Catheter use is associated with negative outcomes in addition to infection, including nonbacterial urethral inflammation, urethral strictures, mechanical trauma, and mobility impairment. ${ }^{13,14}$ Genitourinary trauma events are reported to occur in $1.5 \%$ of catheter-days. ${ }^{10}$

E. CAUTI has been reported to be associated with increased mortality and length of stay, but the association with mortality may be a consequence of confounding by unmeasured clinical variables. ${ }^{15}$

F. Inappropriate treatment of catheter-associated asymptomatic bacteriuria promotes antimicrobial resistance and Clostridium difficile infection in acute care facilities. ${ }^{16}$

III. Risk factors for development of CAUTI

A. The duration of catheterization is the most important risk factor for developing infection. ${ }^{17-19}$ Reducing unnecessary catheter placement and minimizing the duration the catheter remains in situ are the primary strategies for CAUTI prevention.

B. Additional risk factors include female sex, older age, and not maintaining a closed drainage system..$^{20,21}$ Risk factors for CAUTI among pediatric patients are not well described.

C. Risk factors for developing hospital-acquired urinary tract-related BSI include neutropenia, renal disease, and male sex. ${ }^{22}$

IV. Reservoir for transmission

A. The drainage bag of the bacteriuric patient is a reservoir for organisms that may contaminate the environment and be transmitted to other patients through the hands of healthcare personnel. ${ }^{23}$

B. Outbreaks of infections associated with resistant gramnegative organisms attributable to bacteriuria in catheterized patients have been reported. ${ }^{24-26}$

\section{SECTION 2: BACKGROUND-STRATEGIES}

\section{TO DETECT CAUTI}

I. Surveillance definitions

A. The NHSN definition for symptomatic healthcareassociated UTI (http://www.cdc.gov/nhsn) is commonly used but can be difficult to apply to patients with indwelling catheters in place. Localizing signs and symptoms may not be present with a catheter in situ or may not be recognized because of patient comorbidity or inability to communicate due to illness or age. ${ }^{6}$

B. The most common clinical presentation is fever with a positive urine culture result, without other localizing findings. However, given the high prevalence of bacteriuria in patients with an indwelling catheter in place, this definition lacks specificity.
II. Methods for surveillance of CAUTI

A. Surveillance programs that monitor urine cultures through the review of microbiology laboratory results are generally used to detect patients with potential UTIs. Patients with positive urine culture results are then evaluated for the presence of an indwelling urinary catheter and a CAUTI defined by using surveillance criteria. ${ }^{20}$

1. Bacteriuria in patients with an indwelling urinary catheter in place is usually asymptomatic. ${ }^{6}$

2. Microbiologic diagnosis usually requires growth of more than or equal to $10^{5} \mathrm{CFU} / \mathrm{mL}$ of an organism from a urine specimen collected aseptically from the catheter; patients with symptomatic infection may occasionally present with lower quantitative counts, but the frequency of this is uncertain. Lower quantitative counts frequently precede bacteriuria in catheterized patients who do not receive antimicrobials, likely reflecting colonization by catheter biofilm. ${ }^{27}$

B. Use of device-days rather than patient-days as a denominator may mask significant achievements of a successful CAUTI prevention program, as an overall reduction in catheter use may increase the ratio of CAUTIs per device-days despite a total reduction in the number of CAUTIs. ${ }^{28}$

\section{SECTION 3: BACKGROUND-STRATEGIES \\ TO PREVENT CAUTI}

I. Summary of existing guidelines and recommendations (see Table 1)

A. The Centers for Disease Control and Prevention (CDC) published guidelines for prevention of CAUTI in 1981, and these were updated in $2009 .{ }^{20}$ These guidelines provide recommendations for catheter use, catheter insertion, catheter care, and implementation of programs to prevent CAUTI.

B. The IDSA, together with other professional societies, published international guidelines for the management of CAUTI in 2010. ${ }^{21}$

C. The Department of Health in Great Britain published guidelines for preventing infections associated with the insertion and maintenance of short-term indwelling urinary catheters in acute care in $2001,{ }^{29}$ which was updated in $2006 .^{30}$

II. Updated relevant literature

A. Reviews

1. A systematic review in hospitalized patients reported that the use of an intervention including a reminder to staff that a catheter was in place and/or a stop order to prompt removal of unnecessary catheters reduced the CAUTI rate by $53 \%{ }^{31}$

2. A systematic review reported that evidence did not support routine use of indwelling bladder catheters for caesarean section. ${ }^{32}$

3. A Cochrane review and meta-analysis of bladder wash- 
TA BLE 1. Published Guidelines and Recommendations for Prevention of Infections Associated with ShortTerm Indwelling Urethral Catheters

\begin{tabular}{|c|c|c|c|}
\hline & $\operatorname{CDC}(2009)^{20}$ & IDSA (2009) & $\begin{array}{c}\text { NHS Epic } 2 \\
\text { Project }(2007)^{22}\end{array}$ \\
\hline Documentation of catheter insertion & $\mathrm{C}$ & ND & Yes \\
\hline Trained personnel & Yes & ND & Yes \\
\hline Train patients and family & Yes & ND & Yes \\
\hline Hand hygiene & Yes & ND & Yes \\
\hline Evaluation of necessity & Yes & Yes & Yes \\
\hline Evaluation of alternative methods & Yes & Yes & Yes \\
\hline Regular review of ongoing need & Yes & Yes & Yes \\
\hline Choice of catheter & $\mathrm{U}$ & $\mathrm{U}$ & $\mathrm{U}$ \\
\hline Use smallest gauge catheter & Yes & ND & Yes \\
\hline Aseptic technique/sterile equipment & Yes & Yes & Yes \\
\hline Barrier precautions for insertion & Yes & ND & ND \\
\hline Antiseptic cleaning of meatus & $\mathrm{U}$ & ND & No \\
\hline Secure catheter & Yes & ND & No \\
\hline Closed drainage system & Yes & Yes & Yes \\
\hline Obtain urine samples aseptically & Yes & ND & Yes \\
\hline Replace system if break in asepsis & Yes & ND & ND \\
\hline No routine change in catheter & Yes & $\mathrm{U}$ & Yes \\
\hline Routine hygiene for meatal care & Yes & Yes & Yes \\
\hline Avoid irrigation for purpose of preventing infection & Yes & Yes & Yes \\
\hline Separate patients with catheters & $\mathbf{U}$ & $\mathrm{U}$ & ND \\
\hline Use of preconnected system & $\mathrm{C}$ & $\mathrm{C}$ & ND \\
\hline Performance feedback & $\mathrm{C}$ & ND & ND \\
\hline Rates of CAUTI and bacteremia & C & $\mathrm{C}$ & ND \\
\hline
\end{tabular}

NoTe. C, consider; CAUTI, catheter-associated urinary tract infection; CDC, Centers for Disease Control and Prevention; IDSA, Infectious Diseases Society of America; NHS, UK National Health Service; ND, not discussed; $\mathrm{U}$, unresolved (choice left to individual and patient factors).

out policies to prevent blockage of long-term catheters in adults concluded that evidence was too scanty to conclude whether there were benefits. ${ }^{33}$ Trials were generally of poor quality or incompletely reported.

B. Routine postoperative indwelling urethral catheter

1. A prospective randomized trial of thoracic surgery patients managed with epidural analgesia compared morning-after-surgery catheter removal with the catheter remaining in place as long as the thoracic epidural analgesia was functioning. There was a longer time to reach postvoid residuals of less than $200 \mathrm{~mL}$ with early removal but no increased need for recatheterization. CAUTI rates were not reported. ${ }^{34}$

C. Catheter materials

1. A prospective randomized 3-arm trial in $24 \mathrm{UK} \mathrm{Na-}$ tional Health Service (NHS) hospitals compared a standard latex catheter, a latex silver alloy-coated catheter, and a silicone nitrofurazone-impregnated catheter. ${ }^{35}$ The rates of symptomatic culture confirmed that urinary infection at 6 weeks were similar in patients who received either of the 2 latex catheters; a small decrease in rates was noted for patients with the nitrofurazone silicone catheter (odds ratio [OR], 0.68 [97.5\% confidence interval (CI), 0.48-0.99]; $P=$ $.017)$. It is not clear whether the difference was attrib- utable to the silicone or the antimicrobial agent. The nitrofurazone catheter was associated with greater patient discomfort (OR, 1.39 [97.5\% CI, 1.13-1.60]) and increased catheter removal (OR, $1.77[97.5 \% \mathrm{Cl}, 1.51-$ 22.07]). A cost analysis suggested that universal use of a nitrofurazone catheter might be cost-effective in the NHS system, but the analysis was compromised by uncertainty in length-of-stay estimates. ${ }^{36}$

D. Efficacy of prevention programs

The prevention programs reported have varied in components and implementation approaches, and usually multiple interventions have been implemented simultaneously. Decreasing catheter use through restricted indications for placement or duration of catheterization are major components for most programs. All studies used a pre/post intervention trial design.

1. A restrictive urinary catheter policy together with daily review of necessity and discussion of appropriateness of new catheter insertions with emergency medicine and internal medicine physicians decreased catheterization from $17.5 \%$ to $6.6 \%$ of patients. ${ }^{37}$

2. A statewide program in Michigan focused on educating clinicians about appropriate urinary catheter indications and included daily assessment of continued catheter need during nursing rounds. There was 
a decrease in catheter use from $18.1 \%$ to $13.8 \%$, while the proportion of catheters with appropriate indications increased from $44 \%$ to $58 \% .^{38}$

3. A survey-based study compared a random sample of US hospitals to all Michigan hospitals and reported that the Michigan hospitals more frequently participated in collaboratives to reduce HAIs, used bladder scanners to estimate bladder volumes, and used catheter reminders or stop orders and/or nurse-initiated discontinuation. More frequent use of these practices coincided with a $25 \%$ reduction of CAUTI rates in Michigan, compared with $6 \%$ reduction in nonMichigan hospitals. ${ }^{39}$

4. Resident peer-to-peer education for compliance with emergency department urinary catheter placement indications resulted in increased knowledge 3 months after an educational intervention, but there were no differences in catheter use or the proportion of catheters meeting appropriate indications. ${ }^{40}$

5. An educational intervention incorporating catheter indications, timely removal, and correct management, together with initiation of active CAUTI surveillance, resulted in a decrease in catheterization rates from $18.5 \%$ to $9.2 \%(P<.05)$ and a nonsignificant decrease in CAUTI from 6.6 per 1,000 catheter-days to 5.8 per 1,000 catheter-days. ${ }^{41}$

6. Introducing a UTI bundle (avoidance of catheter insertion, maintenance of sterility, product standardization, early catheter removal) in a single-center neurologic ICU significantly decreased catheter utilization from $100 \%$ to $73 \%$ and CAUTI from 13.3 to 4.0 per 1,000 catheter-days. ${ }^{42}$

7. A CAUTI prevention program including education, implementation of common CAUTI prevention practices, outcomes and process measures, and feedback of CAUTI outcomes and process measures was implemented in pediatric ICUs in 6 developing countries, and a decrease in CAUTI rates from 5.9 to 2.6 per 1,000 catheter-days (relative risk, 0.43 [ $95 \% \mathrm{CI}$, $0.21-1.0]$ ) was reported. ${ }^{43}$

E. Implementing programs to prevent CAUTI

1. A multicenter qualitative study identified 4 recurrent themes relevant to hospital use of prevention practices: recognizing the value of early catheter removal, focus on noninfectious complications and presence of a "champion," hospital-specific pilot studies for devices, and external forces, such as public reporting. ${ }^{44}$

2. A statewide initiative in Michigan introduced a bladder bundle to decrease CAUTI using a collaborative model and strategies to facilitate implementation, including "engage and educate," "execute," and "evaluate."

3. A qualitative assessment in 12 hospitals in Michigan of perceptions and key issues influencing implementation of CAUTI prevention practices identified difficulty with nurse and physician engagement, patient and family request for indwelling catheters, and catheter insertion practices and customs in the emergency department as common barriers. ${ }^{46}$

F. Surveillance

1. A simulation model comparing denominators of catheter-days and patient-days reported that CAUTI rates were reduced for 93 of 100 simulations. In $27 \%$ of stimulations the CAUTI rate (with catheter-days as the denominator) increased, while all others showed greater decreases with a denominator of patient-days rather than catheter-days. ${ }^{47}$

2. Data extracted from electronic chart review were $100 \%$ sensitive and $98 \%$ specific compared with bedside review to verify the type and presence of a urinary catheter at one Veterans Affairs hospital. ${ }^{48}$

\section{SECTION 4: RECOMMENDED STRATEGIES FOR CAUTI PREVENTION}

Recommendations are categorized as either (1) basic practices that should be adopted by all acute care hospitals or (2) special approaches that can be considered for use in locations and/or populations within hospitals when HAIs are not controlled by use of basic practices. Basic practices include recommendations where the potential to impact HAI risk clearly outweighs the potential for undesirable effects. Special approaches include recommendations where the intervention is likely to reduce HAI risk but where there is concern about the risks for undesirable outcomes, where the quality of evidence is low, or where evidence supports the impact of the intervention in select settings (eg, during outbreaks) or for select patient populations. Hospitals can prioritize their efforts by initially focusing on implementing the prevention approaches listed as basic practices. If HAI surveillance or other risk assessments suggest that there are ongoing opportunities for improvement, hospitals should then consider adopting some or all of the prevention approaches listed as special approaches. These can be implemented in specific locations or patient populations or can be implemented hospital-wide, depending on outcome data, risk assessment, and/ or local requirements. Each infection prevention recommendation is given a quality-of-evidence grade (see Table 2). Recommendations for preventing and monitoring CAUTI ${ }^{20,21,29,30}$ are summarized in the following section and Table 1.

I. Basic practices for preventing CAUTI: recommended for all acute care hospitals $s^{20,21,29,30}$

A. Provide appropriate infrastructure for preventing CAUTI

1. Provide and implement written guidelines for catheter use, insertion, and maintenance (quality of evidence: III).

a. Develop and implement facility criteria for acceptable indications for indwelling urinary catheter use. While research assessing the appropriateness 
TABLE 2. Grading of the Quality of Evidence

\begin{tabular}{|c|c|}
\hline Grade & Definition \\
\hline I. High & $\begin{array}{l}\text { Highly confident that the true effect lies close to that of the estimated size and direction of the } \\
\text { effect. Evidence is rated as high quality when there is a wide range of studies with no major } \\
\text { limitations, there is little variation between studies, and the summary estimate has a narrow } \\
\text { confidence interval. }\end{array}$ \\
\hline II. Moderate & $\begin{array}{l}\text { The true effect is likely to be close to the estimated size and direction of the effect, but there is } \\
\text { a possibility that it is substantially different. Evidence is rated as moderate quality when there } \\
\text { are only a few studies and some have limitations but not major flaws, there is some variation } \\
\text { between studies, or the confidence interval of the summary estimate is wide. }\end{array}$ \\
\hline III. Low & $\begin{array}{l}\text { The true effect may be substantially different from the estimated size and direction of the effect. } \\
\text { Evidence is rated as low quality when supporting studies have major flaws, there is important } \\
\text { variation between studies, the confidence interval of the summary estimate is very wide, or } \\
\text { there are no rigorous studies, only expert consensus. }\end{array}$ \\
\hline
\end{tabular}

Note. Based on Grades of Recommendation, Assessment, Development, and Evaluation (GRADE) ${ }^{76}$ and the Canadian Task Force on Preventive Health Care. ${ }^{77}$

of indwelling catheter use is limited, expert consensus-derived catheter indications have been developed. ${ }^{20}$ Examples of appropriate indications for indwelling urethral catheter use are limited and include the following:

$i$. Perioperative use for selected surgical procedures, such as urologic surgery or surgery on contiguous structures of the genitourinary tract; prolonged surgery; large volume infusions or diuretics during surgery; intraoperative monitoring of urine output needed.

ii. Hourly assessment of urine output in patients in an ICU.

iii. Management of acute urinary retention and urinary obstruction.

iv. Assistance in healing of open pressure ulcers or skin grafts for selected patients with urinary incontinence.

v. As an exception, at patient request to improve comfort (eg, end-of-life care).

2. Ensure that only trained, dedicated personnel insert urinary catheters (quality of evidence: III).

3. Ensure that supplies necessary for aseptic technique for catheter insertion are available and conveniently located (quality of evidence: III).

4. Implement a system for documenting the following in the patient record: physician order for catheter placement, indications for catheter insertion, date and time of catheter insertion, name of individual who inserted catheter, nursing documentation of placement, daily presence of a catheter and maintenance care tasks, and date and time of catheter removal. Record criteria for removal and justification for continued use (quality of evidence: III).

a. Record in a standard format for data collection and quality improvement purposes and keep accessible documentation of catheter placement (including indication) and removal. b. Utilize electronic documentation that is searchable, if available.

5. Ensure that there are sufficient trained personnel and technology resources to support surveillance for catheter use and outcomes (quality of evidence: III).

B. Perform surveillance for CAUTI if indicated on the basis of facility risk assessment or regulatory requirements

1. Identify the patient groups or units in which to conduct surveillance on the basis of risk assessment, considering frequency of catheter use and potential risk (eg, types of surgery, obstetrics, critical care; quality of evidence: III).

2. Use standardized criteria, such as NHSN definitions, to identify patients who have a CAUTI (numerator data; quality of evidence: III).

3. Collect information on catheter-days and patientdays (denominator data) and indications for catheter insertion for all patients in the patient groups or units being monitored (quality of evidence: III).

4. Calculate CAUTI rates and/or standardized infection ratio (SIR) for target populations (quality of evidence: III).

5. Use surveillance methods for case finding that are documented to be valid and appropriate for the institution (quality of evidence: III).

6. Consider providing unit-specific feedback (quality of evidence: III).

C. Provide education and training

1. Educate healthcare personnel involved in the insertion, care, and maintenance of urinary catheters about CAUTI prevention, including alternatives to indwelling catheters, and procedures for catheter insertion, management, and removal (quality of evidence: III).

2. Assess healthcare professional competency in catheter use, catheter care, and maintenance (quality of evidence: III). 
D. Use appropriate technique for catheter insertion

1. Insert urinary catheters only when necessary for patient care and leave in place only as long as indications remain (quality of evidence: II).

2. Consider other methods for bladder management, such as intermittent catheterization, where appropriate (quality of evidence: II).

3. Practice hand hygiene (based on CDC or World Health Organization guidelines) immediately before insertion of the catheter and before and after any manipulation of the catheter site or apparatus (quality of evidence: III).

4. Insert catheters following aseptic technique and using sterile equipment (quality of evidence: III).

5. Use sterile gloves, drape, and sponges; a sterile or antiseptic solution for cleaning the urethral meatus; and a sterile single-use packet of lubricant jelly for insertion (quality of evidence: III).

6. Use as small a catheter as possible consistent with proper drainage, to minimize urethral trauma (quality of evidence: III).

E. Ensure appropriate management of indwelling catheters

1. Properly secure indwelling catheters after insertion to prevent movement and urethral traction (quality of evidence: III).

2. Maintain a sterile, continuously closed drainage system (quality of evidence: III).

3. Replace the catheter and the collecting system using aseptic technique when breaks in aseptic technique, disconnection, or leakage occur (quality of evidence: III).

4. For examination of fresh urine, collect a small sample by aspirating urine from the needleless sampling port with a sterile syringe/cannula adaptor after cleansing the port with disinfectant (quality of evidence: III).

5. Obtain larger volumes of urine for special analyses aseptically from the drainage bag (quality of evidence: III).

6. Maintain unobstructed urine flow (quality of evidence: III).

a. Keep the collecting bag below the level of the bladder at all times; do not place the bag on the floor (quality of evidence: III).

b. Keep catheter and collecting tube free from kinking (quality of evidence: III).

c. Empty the collecting bag regularly using a separate collecting container for each patient. Avoid touching the draining spigot to the collecting container (quality of evidence: III).

7. Employ routine hygiene; cleaning the meatal area with antiseptic solutions is unnecessary (quality of evidence: III).

II. Special approaches for preventing CAUTI

Perform a CAUTI risk assessment. These special approaches are recommended for use in locations and/or populations within the hospital with unacceptably high CAUTI rates or SIRs despite implementation of the basic CAUTI prevention strategies listed previously.

1. Implement an organization-wide program to identify and remove catheters that are no longer necessary using one or more methods documented to be effective (quality of evidence: II).

a. Develop and implement institutional policy requiring periodic (usually daily) review of the necessity of continued catheterization.

b. Consider utilizing electronic or other types of reminders (Figure 1) of the presence of a catheter and required criteria for continued use. ${ }^{27}$ Some examples include the following:

i. Automatic stop orders requiring review of current indications and renewal of order for continuation of the indwelling catheter.

ii. Standardized electronic or paper reminders of persistent catheters together with current catheter indications (Figure 1) targeting either physicians or nurses.

c. Conduct daily review during rounds of all patients with urinary catheters by nursing and physician staff to ascertain the necessity of continuing catheter use.

2. Develop a protocol for management of postoperative urinary retention, including nurse-directed use of intermittent catheterization and use of bladder scanners (quality of evidence: II).

a. If bladder scanners are used, clearly state indications, train nursing staff in their use, and disinfect between patients according to manufacturers' instructions.

3. Establish a system for analyzing and reporting data on catheter use and adverse events from catheter use (quality of evidence: III).

a. Calculate device utilization ratio (device-days/ patient-days) to supplement CAUTI rates.

b. Define and monitor adverse outcomes in addition to CAUTI, including catheter obstruction, unintended removal, catheter trauma, or reinsertion within 24 hours of removal.

c. For analysis, stratify measurements of catheter use and adverse outcomes by relevant risk factors (eg, sex, age, ward, duration). Review data in a timely fashion and report to appropriate stakeholders.

III. Approaches that should not be considered a routine part of CAUTI prevention

1. Do not routinely use antimicrobial/antiseptic-impregnated catheters (quality of evidence: I).

2. Do not screen for asymptomatic bacteriuria in catheterized patients (quality of evidence: II).

3. Do not treat asymptomatic bacteriuria in catheterized patients except before invasive urologic procedures (quality of evidence: I).

4. Avoid catheter irrigation (quality of evidence: II).

a. Do not perform continuous irrigation of the bladder 


\section{**URINARY CATHETER REMINDER**}

DATE: -1

This patient has had an indwelling urethral catheter since

Please indicate below EITHER (1) that the catheter should be removed OR (2) that the catheter should be retained. If the catheter should be retained, please state ALL of the reasons that apply.

Please discontinue indwelling urethral catheter; $\mathbf{O R}$

Please continue indwelling urethral catheter because patient requires indwelling catheterization for the following reasons (please check all that apply):

Urinary retention

Very close monitoring of urine output and patient unable to use urinal or bedpan

Open wound in sacral or perineal area and patient has urinary incontinence

Patient too ill or fatigued to use any other type or urinary collection strategy

Patient had recent surgery

Management of urinary incontinence on patient's request

Other-please specify

FIGURE 1. Urinary catheter reminder. ${ }^{42}$ From Saint et al. ${ }^{78}$

with antimicrobials as a routine infection prevention measure.

b. If continuous irrigation is being used to prevent obstruction, maintain a closed system.

5. Do not use systemic antimicrobials routinely as prophylaxis (quality of evidence: III).

6. Do not change catheters routinely (quality of evidence: III).
IV. Unresolved issues

1. Use of antiseptic solution versus sterile saline for meatal cleaning before catheter insertion.

2. Use of urinary antiseptics (eg, methenamine) to prevent UTI.

3. Use of catheters with valves.

4. Spatial separation of patients with urinary catheters in place to prevent transmission of pathogens that could 
colonize urinary drainage systems.

5. Antimicrobial prophylaxis at catheter removal to prevent symptomatic infection.

\section{SECTION 5: PERFORMANCE MEASURES}

I. Internal reporting

These performance measures are intended to support internal hospital quality improvement efforts and do not necessarily address external reporting needs. The process and outcome measures suggested here are derived from published guidelines, other relevant literature, and the opinions of the authors. Report both process and outcome measures to senior hospital leadership, nursing leadership, and clinicians who care for patients at risk for CAUTI.

A. Process measures

1. Compliance with documentation of catheter insertion and removal dates.

a. Conduct random audits of selected units and calculate compliance rate:

$i$. Numerator: number of patients with urinary catheters in the unit with proper documentation of insertion and removal dates.

ii. Denominator: number of patients in the unit with a urinary catheter in place at some time during admission.

iii. Multiply by 100 so that the measure is expressed as a percentage.

2. Compliance with documentation of indication for catheter placement.

a. Conduct random audits of selected units and calculate compliance rate:

i. Numerator: number of patients with urinary catheters in the unit with an appropriate indication for the catheter.

ii. Denominator: number of patients in the unit with a urinary catheter in place.

iii. Multiply by 100 so that the measure is expressed as a percentage.

B. Outcome measures

1. Assess rates of symptomatic CAUTI, stratified by risk factors (eg, ward).

a. Although the validity of the current $\mathrm{CDC} / \mathrm{NHSN}$ definition for symptomatic CAUTI for comparison of facility-to-facility outcomes is not established, measurement of rates allows an individual facility to gauge the longitudinal impact of implementation of prevention strategies. ${ }^{20}$

i. Numerator: number of symptomatic CAUTI in each location monitored.

ii. Denominators: (a) total number of urinary catheter-days for all patients in each location with an indwelling urinary catheter; $(b)$ total number of patient-days for all patients in each location monitored. iii. Multiply by 1,000 so that measure is expressed as cases per 1,000 catheter-days or by 10,000 to express as cases per 10,000 patient-days.

2. Rates of BSI attributable to CAUTI.

a. Use NHSN definition for secondary BSI (available at http://www.cdc.gov/nhsn.html) when blood culture organism matches urine specimens and patient meets criteria for CAUTI.

i. Numerator: number of episodes of BSIs attributable to CAUTI.

ii. Denominator: total number of urinary catheterdays for all patients in each location monitored who have an indwelling urinary catheter in place.

iii. Multiply by 1,000 so that the measure is expressed as cases per 1,000 catheter-days.

3. SIR.

a. The SIR is a summary measure used to track HAIs at a national, state, or facility level over time. SIR adjusts for the different types of patients in healthcare facilities.

i. The ratio is calculated by dividing the observed number of CAUTIs by the predicted number of CAUTIs.

ii. The predicted number of infections is an estimated number of CAUTIs based on infections reported to NHSN during a baseline period (currently 2009 for CAUTI, risk adjusted for patient care location and facility characteristics).

II. External reporting

There are many challenges in providing useful information to consumers and other stakeholders while preventing unintended adverse consequences of public reporting of HAIs. ${ }^{49}$ Recommendations for public reporting of HAIs have been provided by the Healthcare Infection Control Practices Advisory Committee, ${ }^{50}$ the HealthcareAssociated Infection Working Group of the Joint Public Policy Committee, ${ }^{51}$ and the National Quality Forum. ${ }^{52}$ In January 2012, most acute care facilities began reporting CAUTIs from adult and pediatric ICUs to NHSN to meet the requirements of the Centers for Medicare and Medicaid Services Inpatient Prospective Payment System FY2012 final rule.

The validity of the current $\mathrm{CDC} / \mathrm{NHSN}$ definition for CAUTI for comparing facility-to-facility outcomes is not established, so exercise caution in interfacility comparison of CAUTI rates. Use of hospital claims data to compare hospital-acquired CAUTI rates has also not yet been validated. $^{53}$

A. State and local requirements

1. Hospitals in states that have mandatory reporting requirements must collect and report the data required by the state. For information on state and federal requirements, check with your state or local health department. 


\section{TABLE 3. Fundamental Elements of Accountability for Healthcare-Associated Infection Prevention}

Senior management is responsible for ensuring that the healthcare system supports an infection prevention and control (IPC) program that effectively prevents healthcare-associated infections (HAls) and the transmission of epidemiologically important pathogens

Senior management is accountable for ensuring that an adequate number of trained personnel are assigned to the IPC program and adequate staffing of other departments that play a key role in HAI prevention (eg, environmental services)

Senior management is accountable for ensuring that healthcare personnel, including licensed and nonlicensed personnel, are adequately trained and competent to perform their job responsibilities

Direct healthcare providers (such as physicians, nurses, aides, and therapists) and ancillary personnel (such as environmental service and equipment processing personnel) are responsible for ensuring that appropriate IPC practices are used at all times (including hand hygiene, standard and isolation precautions, and cleaning and disinfection of equipment and the environment)

Senior and unit leaders are responsible for holding personnel accountable for their actions

IPC leadership is responsible for ensuring that an active program to identify HAIs is implemented, that HAI data are analyzed and regularly provided to those who can use the information to improve the quality of care (eg, unit staff, clinicians, and hospital administrators), and that evidence-based practices are incorporated into the program

Senior and unit leaders are accountable for ensuring that appropriate training and educational programs to prevent HAIs are developed and provided to personnel, patients, and families

Personnel from the IPC program, the laboratory, and information technology departments are responsible for ensuring that systems are in place to support the surveillance program

\section{B. External quality initiatives}

1. Hospitals that participate in external quality initiatives must collect and report the data required by the initiative.

\section{SECTION 6: EXAMPLES OF}

\section{IMPLEMENTATION STRATEGIES}

Accountability is an essential principle for preventing HAIs. It provides the necessary translational link between science and implementation. Without clear accountability, scientifically based implementation strategies will be used in an inconsistent and fragmented way, decreasing their effectiveness in preventing HAIs. Accountability begins with the chief executive officer and other senior leaders who provide the imperative for HAI prevention, thereby making HAI prevention an organizational priority. Senior leadership is accountable for providing adequate resources needed for effective implementation of an HAI prevention program. These resources include necessary personnel (clinical and nonclinical), education, and equipment (Table 3 ).

Interventions to assist with program implementation that have been reported to be associated with improved outcomes are provided in this section. The references provided are published studies of CAUTI quality improvement projects that specifically describe outcomes. These programs are normally multifactorial and include elements of most or all of the 4 categories of implementation approaches. Practical approaches for problem solving of potential barriers to implementation are provided in Table 4.

\section{Engage}

Quality improvement projects directed toward improving compliance with CAUTI guidelines have used various techniques to engage the hospital staff to raise awareness of the issue and increase buy-in.
A. Develop a multidisciplinary team

1. Physician-led team ${ }^{54-56}$

2. Nursing-led team ${ }^{57-59}$

3. Leadership of team not specified ${ }^{42,58,60-64}$

B. Involve local champions to promote the program ${ }^{57,63,65,66}$

C. Utilize peer networking ${ }^{43,62,66}$

II. Educate

Education of the hospital staff can include in-person sessions or educational material available in paper format or electronically. The educational sessions may outline the evidence behind the guidelines, indicate the goals of the program, and target specific aspects of CAUTI prevention.

A. Provide educational sessions

1. Appropriate catheter care $\mathrm{el}^{4-43,57,58,63,67-70}$

2. Appropriate indications for catheter insertion ${ }^{37,41,43,55,57,61,65,67}$

3. Insertion technique $e^{42,43,62,67,69,70}$

4. Hand hygiene education ${ }^{43,67,69}$

5. Physician-directed education ${ }^{42,66}$

6. Alternatives for indwelling catheters ${ }^{71}$

B. Provide educational materials

1. Indications for urinary catheter utilization ${ }^{65}$

2. Decision-making algorithim ${ }^{57}$

3. Bedside binders ${ }^{57}$

4. Unit-based educational materials ${ }^{72}$

5. Online learning materials ${ }^{63}$

6. Patient/family educational material ${ }^{6.3}$

III. Execute

The process for making quality improvement changes employs new protocols and algorithms. Interventions may be grouped into "bundles" of practices to be implemented simultaneously. Computer order entry is also increasingly being used to prompt change.

A. Standardize care processes

1. Provide daily nursing reminders to physicians to re- 


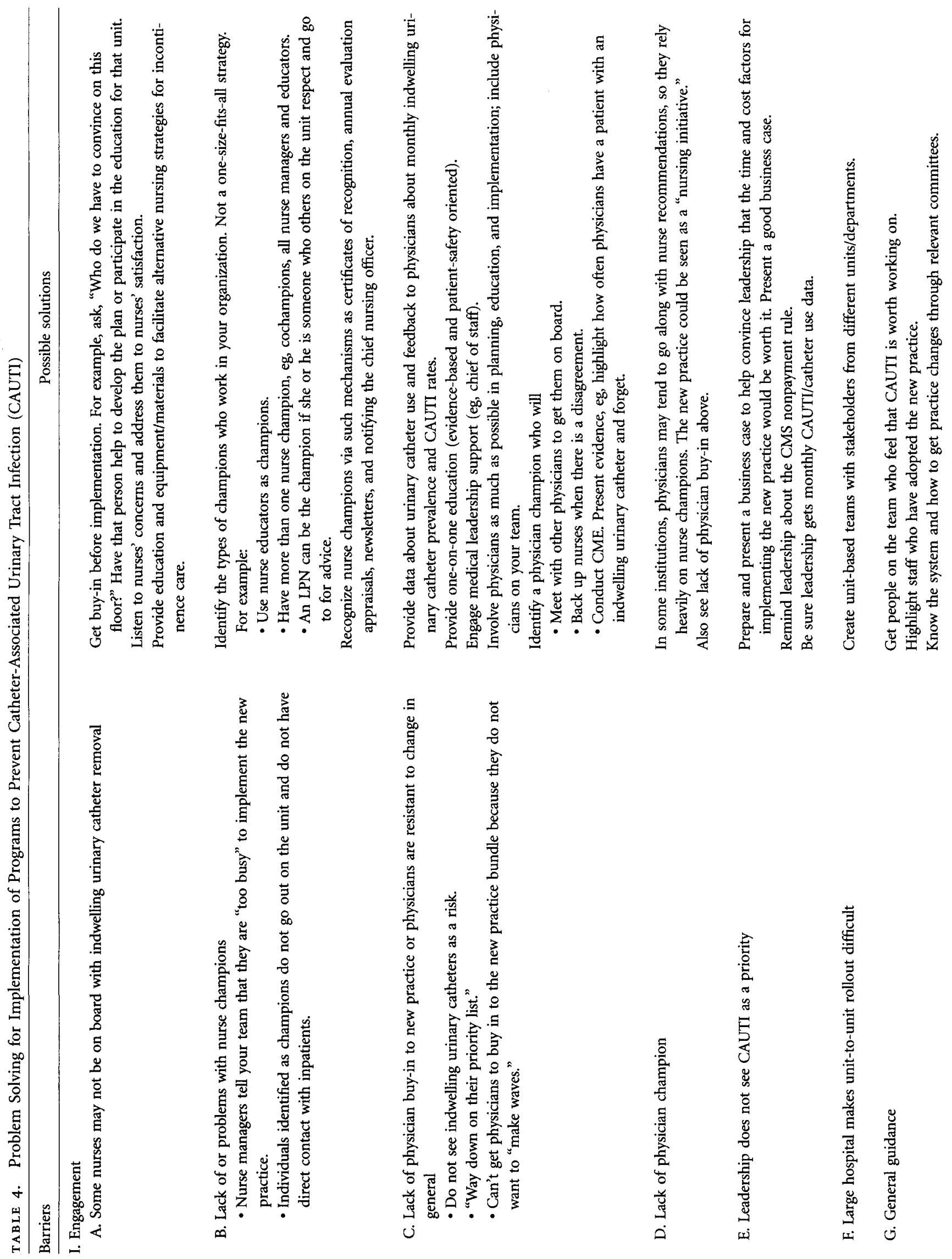




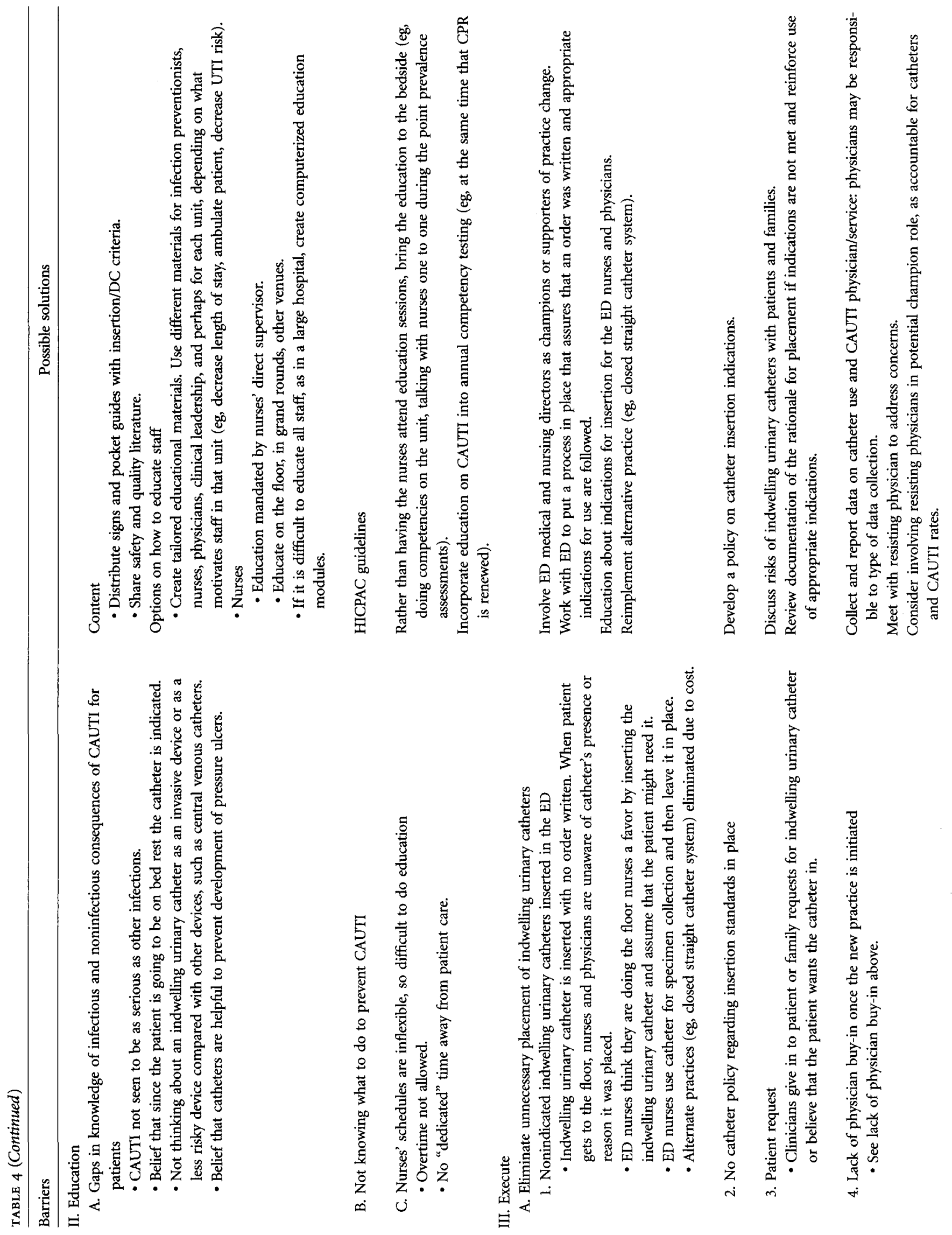




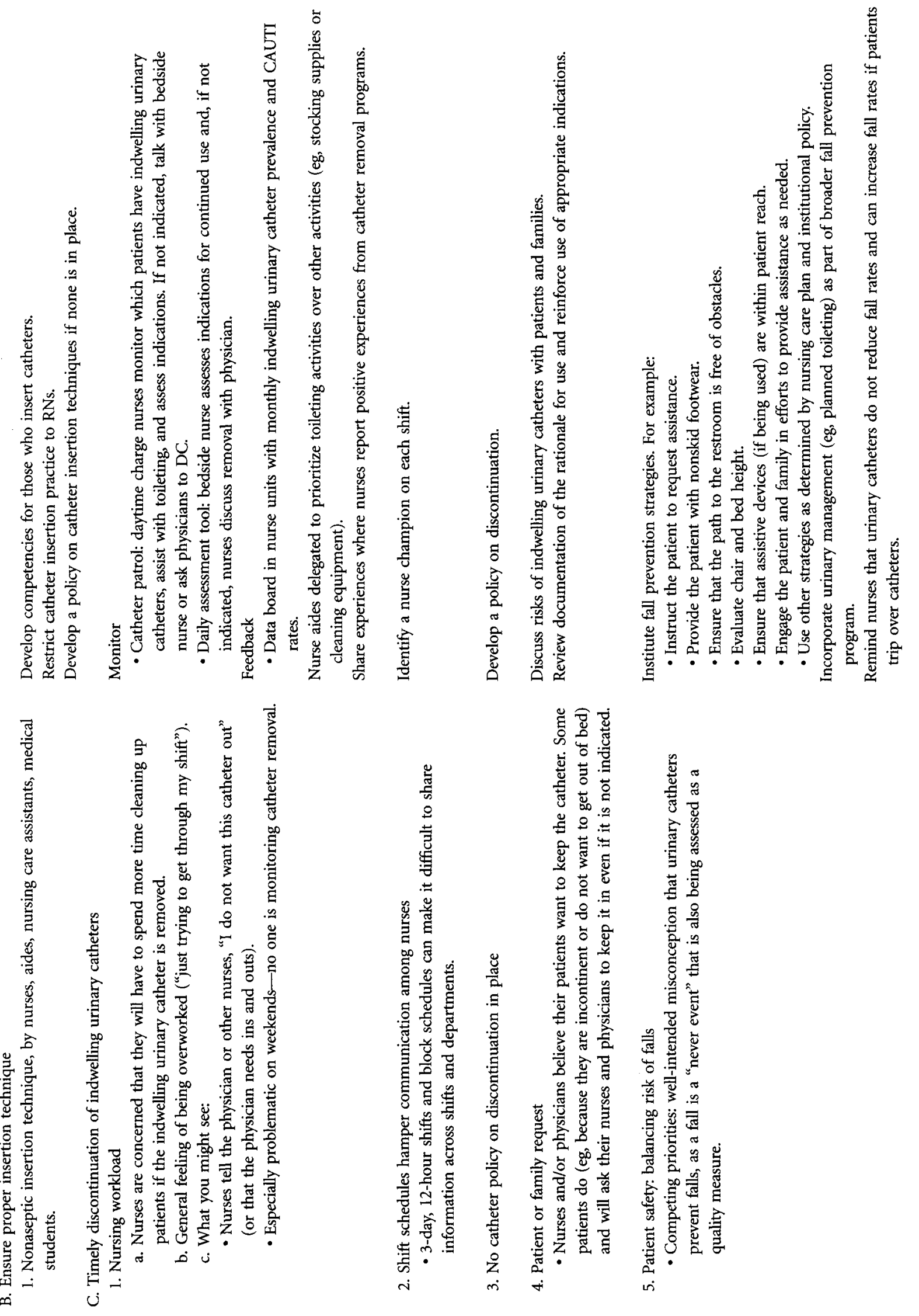



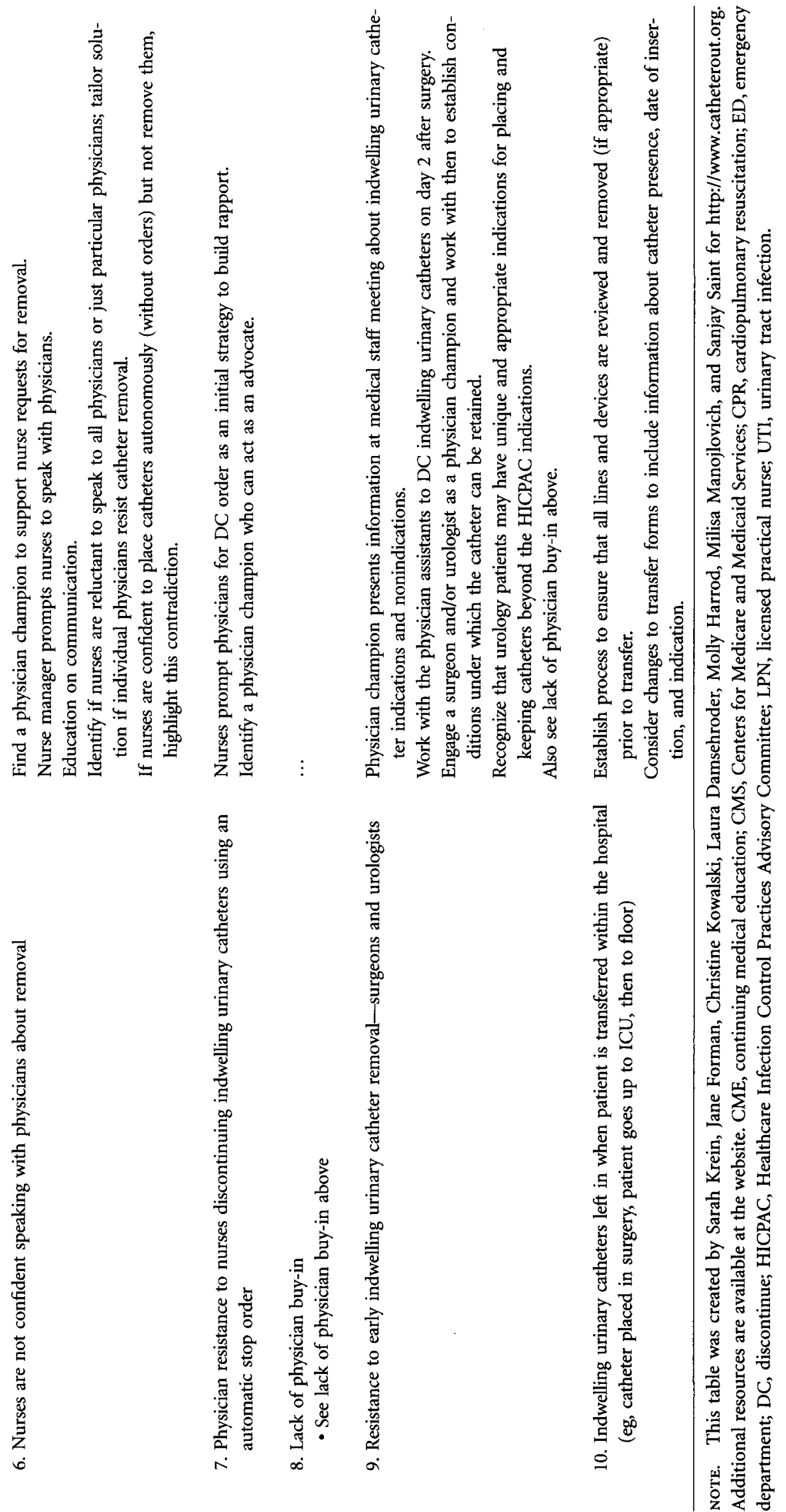
move unnecessary catheters ${ }^{55,56,61,63-65,73}$

2. Standardize indications for urinary catheter placement ${ }^{42,55-57,60,65}$

3. Utilize bladder bundle ${ }^{42,54,66,69,72,74}$

4. Develop a nurse-driven protocol to discontinue catheter if no longer meeting criteria ${ }^{42,58,60,71}$

5. Employ computerized order entry

a. Admitting physician alert requiring confirmation of continued indication for previously placed catheters $^{71}$

b. Change of physician order set from "insert Foley catheter" to patient-initiated "void on call" for appropriate procedures ${ }^{69}$

c. Mandatory order to remove catheter at 5 days $^{70}$

d. Best-practice order sets ${ }^{42}$

6. Use prewritten stop orders ${ }^{62,75}$

7. Utilize bladder scanners to measure urine volume ${ }^{57,62,63,71}$

8. Standardize products $\mathrm{s}^{42,58,62-64}$

9. Increase availability of bedside commodes ${ }^{63}$

10. Conduct individual case reviews ${ }^{42}$

11. Create redundancy of educational materials

a. Posters in units ${ }^{57,62}$

b. Pocket cards ${ }^{62}$

\section{Evaluate}

The success of a CAUTI quality improvement program can be measured by decreased rates of CAUTI, by decreased catheter-days, and by uptake of a new intervention. Most programs have found that providing feedback to the hospital or unit increases awareness.

A. Measure performance

1. Compliance with bundle ${ }^{43,67,74}$

2. Compliance with hand hygiene $e^{43,67,72,74}$

B. Provide feedback to staff

1. CAUTI rates by ward ${ }^{58,68}$

2. CAUTI rate by hospital ${ }^{43,56,67}$

3. Hand hygiene rate ${ }^{43,67}$

4. Catheter care compliance $\mathrm{e}^{43,67}$

5. Costs of $\mathrm{UTI}^{56}$

\section{ACKNOWLEDGMENTS}

Disclaimer. C.G.-The findings and conclusions in this report are those of the authors and do not necessarily represent the official position of the Centers for Disease Control and Prevention.

Potential conflicts of interest. Authors report the following. E.L.-research grants/contracts: Cangene Corporation, antibody responses to $C$. difficileassociated diarrhea; research with Virox Industries, HAI response to environmental disinfection. L.E.N.-advisory/consultant role: Cerena, Johnson \& Johnson. D.A.P.—advisory/consultant role: InVentiv; honoraria: Health Research and Educational Trust/American Hospital Association, Rand Health. A.M.P.-served as a speaker for Bard; served as a speaker and author for Covidien. S.S.-honoraria and speaking fees for lectures on healthcareassociated infection prevention, implementation science, and patient safety from hospitals, academic medical centers, professional societies, and nonprofit foundations (none of these activities are related to speakers' bureaus); medical advisory board: Doximity (a new social networking site for physi- cians), Jvion (a healthcare technology company). S.E.C., C.G., L.L.M., J.M., D.S.Y.-nothing to disclose.

Address correspondence to Lindsay E. Nicolle, MD, GG-443 Health Sciences Centre, 820 Sherbrook Street, Winnipeg, Manitoba R3A 1R9, Canada (Inicolle@exchange.hsc.mb.ca).

\section{REFERENCES}

1. Lo E, Nicolle L, Classen D, et al. Strategies to prevent catheterassociated urinary tract infections in acute care hospitals. Infect Control Hosp Epidemiol 2008;29(suppl 1):S41-S50.

2. Yokoe DS, Anderson DJ, Berenholtz SM, et al. Introduction to "A Compendium of Strategies to Prevent Healthcare-Associated Infections in Acute Care Hospitals: 2014 Updates." Infect Control Hosp Epidemiol 2014;35(5):455-459 (in this issue).

3. Saint $S$, Chenoweth CE. Biofilms and catheter-associated urinary tract infections. Infect Dis Clin North Am 2003;17:411-432.

4. Weber DJ, Sickbert-Bennett EE, Gould CV, Brown VM, Huslage $\mathrm{K}$, Rutala WA. Incidence of catheter-associated and non-catheter-associated urinary tract infections in a healthcare system. Infect Control Hosp Epidemiol 2011;32:822-823.

5. Weinstein JW, Mazon D, Pantelick E, Reagan-Cirincione P, Dembry LM, Hierholzer WJ. A decade of prevalence surveys in a tertiary-care center: trends in nosocomial infection rates, device utilization, and patient acuity. Infect Control Hosp Epidemiol 1999;20:543-548.

6. Tambyah PA, Maki DG. Catheter-associated urinary tract infection is rarely symptomatic. Arch Intern Med 2000;160:678-687.

7. Burton DC, Edwards JR, Srinivason A, Fridkin SK, Gould CV. Trends in catheter-associated urinary tract infections in adult intensive care units-United States, 1990-2007. Infect Control Hosp Epidemiol 2011;32:748-756.

8. Tambyah PA, Knasinski V, Maki DG. The direct costs of nosocomial catheter-associated urinary tract infection in the era of managed care. Infect Control Hosp Epidemiol 2002;23:27-31.

9. Centers for Disease Control and Prevention (CDC). National Healthcare Safety Network (NHSN) Report, Data Summary for 2011, Device-Associated Module. Atlanta: CDC, 2013. http:// www.cdc.gov/nhsn/PDFs/dataStat/NHSN-Report-2011-Data -Summary.pdf. Accessed November 28, 2013.

10. Leuck A-M, Wright D, Ellingson L, Kraemer L, Kuskowski MA, Johnson JR. Complications of Foley catheters-is infection the greatest risk? J Urol 2012;187:1662-1666.

11. Centers for Disease Control and Prevention (CDC). $2011 \mathrm{Na}$ tional and State Healthcare-Associated Infections Standardized Infection Ratio Report. Atlanta: CDC, 2013. http://www.cdc.gov /hai/pdfs/SIR/SIR-Report_02_07_2013.pdf. Accessed November 28, 2013.

12. Fortin E, Rocher I, Frenette C, Temblay C, Quach C. Healthcareassociated bloodstream infections secondary to a urinary focus: the Quebec Provincial Surveillance results. Infect Control Hosp Epidemiol 2012;33:456-462.

13. Hollingsworth SM, Rogers MA, Krein SL, et al. Determining the noninfectious complications of indwelling urethral catheters: a systematic review and meta-analysis. Ann Intern Med 2013;159: 401-410.

14. Saint S, Baker PD, McDonald LL, Ossenkop K. Urinary catheters: what type do men and their nurses prefer? J Am Geriatr Soc 1999;47:1453-1457.

15. Chant C, Smith DM, Marshall JC, Friedrich JO. Relationship 
of catheter-associated urinary tract infection to mortality and length of stay in critically ill patients: a systematic review and meta-analysis of observational studies. Crit Care Med 2011;39: 1167-1173.

16. Cope M, Cevallos ME, Cadle RM, Daroviche RO, Musher DM, Trautner BW. Inappropriate treatment of catheter associated asymptomatic bacteriuria in a tertiary care hospital. Clin Infect Dis 2009;48:1182-1188.

17. Johnson JR, Roberts PL, Olsen RJ, Moyer KA, Stamm WE. Prevention of catheter-associated urinary tract infection with a silver-oxide-coated urinary catheter: clinical and microbiologic correlation. I Infect Dis 1990;162:1145-1150.

18. Huth TS, Burke JP, Larsen RA, Classen DC, Stevens LE. Randomized trial of meatal care with silver sulfadiazine cream for the prevention of catheter-associated bacteriuria. I Infect Dis 1992;165:14-18.

19. Riley DK, Classen DC, Stevens LE, Burke JP. A large, randomized clinical trial of a silver-impregnated urinary catheter: lack of efficacy and staphylococcal superinfection. Am J Med 1995;98: 349-356.

20. Gould CV, Umscheid CA, Agarwal RK, Kuntz G, Pegues DA. Healthcare Infection Control Practices Advisory Committee (HICPAC): guideline for prevention of catheter-associated urinary tract infections, 2009. http://www.cdc.gov/hicpac/cauti 1001_cauti.html.

21. Hooton TM, Bradley SF, Cardenas DD, et al. Diagnosis, prevention and treatment of catheter-associated urinary tract infection in adults: 2009 international clinical practice guidelines from the Infectious Diseases Society of America. Clin Infect Dis 2010;50:625-663.

22. Greene MT, Chang R, Kuhn L, et al. Predictors of hospitalacquired urinary tract-related bloodstream infection. Infect Control Hosp Epidemiol 2012;33:1001-1007.

23. Bukhari SS, Sanderson PJ, Richardson DM, Kaufman ME, Aucken HM, Cookson BD. Endemic cross-infection in an acute medical ward. J Hosp Infect 1993;24:261-271.

24. Schaberg DR, Weinstein RA, Stamm WE. Epidemics of nosocomial urinary tract infection caused by multiply resistant gramnegative bacilli: epidemiology and control. J Infect Dis 1976;133: 363-366.

25. Jarvis WR, Munn VP, Highsmith AK, Culver DH, Hughes JM. The epidemiology of nosocomial infections caused by Klebsiella pneumoniae. Infect Control 1985;6:68-74.

26. Yoon HJ, Choi JY, Park YS, et al. Outbreaks of Serratia marcescens bacteriuria in a neurosurgical intensive care unit of a tertiary care teaching hospital: a clinical, epidemiologic, and laboratory perspective. Am J Infect Control 2005;33:595-601.

27. Stark RP, Maki DG. Bacteriuria in the catheterized patient: what quantitative level of bacteriuria is relevant? N Engl J Med 1984; 311:560-564.

28. Oliver-Wright M, Kharaseh M, Beaumont JL, Peterson LR, Robicsek A. Reporting catheter-associated urinary tract infections: denominator matters. Infect Control Hosp Epidemiol 2011;32: 635-640

29. Pratt RJ, Pellowe C, Loveday HP, Robinson N, Smith GW; Epic Guideline Development Team. Guidelines for preventing infections associated with the insertion and maintenance of shortterm indwelling urethral catheters in acute care. I Hosp Infect 2001;47(suppl):S39-S46.

30. Pratt RJ, Pellowe CM, Wilson JA, et al. Epic 2: national evidencebased guidelines for preventing healthcare-associated infections in NHS hospitals in England. J Hosp Infect 2007;65(suppl):S1S64.

31. Meddings J, Rogers MA, Krein SL, et al. Reducing unnecessary urinary catheter use and other strategies to prevent catheterassociated urinary tract infection: an integrative review. $B M J$ Qual Saf 2013. Electronically published ahead of print. doi: 10.1136/bmjqs-2012-001774.

32. Li L, Wen J, Wang L, Li YP, Li Y. Is routine indwelling catheterization of the bladder for caesarean section necessary? a systematic review. BJOG 2011;118:400-409.

33. Hagen S, Sinclair L, Cross S. Washout policies in long-term indwelling urinary catheterization in adults. Cochrane Database Syst Rev 2010;(3):CD004012.

34. Zaouter C, Wuethrich P, Miccoli M, Carli F. Early removal of urinary catheter leads to greater post-void residuals in patients with thoracic epidural. Acta Anaestheiol Scand 2012;56(8):10201025.

35. Pickard R, Lam T, MacLennan G, et al. Antimicrobial catheters for reduction of symptomatic urinary tract infection in adults requiring short-term catheterisation in hospital: a multicentre randomised controlled trial. Lancet 2012;380:1927-1935.

36. Pickard R, Lam T, MacLennan G, et al. Types of urethral catheter for reducing symptomatic urinary tract infections in hospitalised adults requiring short-term catheterisation: multicentre randomised controlled trial and economic evaluation of antimicrobial- and antiseptic-impregnated urethral catheters (the CATHETER trial). Health Technol Assess 2012;16(47). doi: $10.3310 / \mathrm{hta} 16470$.

37. Shimoni Z, Rodrig J, Kamma N, Froom P. Will more restrictive indications decrease rates of urinary catheterization? an historical comparative study. BMJ Open 2012;2:e000473.

38. Fakih MG, Watson SR, Greene MT, et al. Reducing inappropriate urinary catheter use: a statewide effort. Arch Intern Med 2012; 172:255-260.

39. Saint S, Greene MT, Kowalski CP, Watson SR, Hofer TP, Krein SL. Preventing catheter-associated urinary tract infection in the United States: a national comparative study. JAMA Intern Med 2013;173(10):874-879.

40. Dyc NG, Pena ME, Shemes SP, Rey JE, Szpunar SM, Fakih MG. The effect of resident peer-to-peer education on compliance with urinary catheter placement indications in the emergency department. Postgrad Med J 2011;87:814-818.

41. Marigliano A, Barbadoro P, Pennacchietti L, D'Errico MM, Prospero $E$. Active training and surveillance: 2 good friends to reduce urinary catheterization rate. Am J Infect Control 2012;40:692-695.

42. Titsworth WL, Hester J, Correia T, et al. Reduction of catheterassociated urinary tract infections among patients in a neurological intensive care unit: a single institution's success. I Neurosurg 2012;116:911-920.

43. Rosenthal VD, Ramachandran B, Ducnas L, et al. Findings of the International Nosocomial Infection Control Consortium (INICC), part I: effectivenesss of a multidimensional infection control approach on catheter-associated urinary tract infection rates in pediatric intensive care units of 6 developing countries. Infect Control Hosp Epidemiol 2012;33:696-703.

44. Saint $S$, Kowalski CP, Forman J, et al. A multicenter qualitative study on preventing hospital-acquired urinary tract infection in US hospitals. Infect Control Hosp Epidemiol 2008;29:333-341.

45. Saint S, Olmsted RN, Fakih MG, et al. Translating health careassociated urinary tract infection prevention research into prac- 
tice via the bladder bundle. Jt Comm J Qual Patient Saf 2009; 35:449-455.

46. Krein SL, Kowalski CP, Harrod M, Forman J, Saint S. Barriers to reducing urinary catheter use: a qualitative assessment of a statewide initiative. JAMA Intern Med 2013;173(1):881-886.

47. Fakih MG, Greene MT, Kennedy EH, et al. Introducing a population-based outcome measure to evaluate the effect of interventions to reduce catheter-associated urinary tract infection. Am J Infect Control 2012;40:359-364.

48. Burns AC, Petersen NJ, Garza A, et al. Accuracy of a urinary catheter surveillance protocol. Am J Infect Control 2012;40:55-58.

49. Wong ES, Rupp ME, Mermel L, et al. Public disclosure of healthcare-associated infections: the role of the Society for Healthcare Epidemiology of America. Infect Control Hosp Epidemiol 2005; 26(2):210-212.

50. McKibben L, Horan TC, Tokars JI, et al. Guidance on public reporting of healthcare-associated infections: recommendations of the Healthcare Infection Control Practices Advisory Committee. Infect Control Hosp Epidemiol 2005;26(6):580-587.

51. Healthcare-Associated Infection Working Group of the Joint Public Policy Committee. Essentials of Public Reporting of Healthcare-Associated Infections: A Tool Kit. Atlanta: Centers for Disease Control and Prevention, 2007. http://www.cdc.gov /ncidod/dhqp/pdf/ar/06_107498_Essentials_Tool_Kit.pdf. Accessed April 6, 2007.

52. National Quality Forum. National Voluntary Consensus Standards, Endorsed November 15, 2007. Washington, DC: National Quality Forum, 2007. http://www.qualityforum.org/pdf/news /lsCSACMeasures.pdf. Accessed December 20, 2007.

53. Meddings JA, Reichert H, Rogers MA, Saint S, Stephansky J, McMahon LF. Effect of nonpayment for hospital-acquired catheter-associated urinary tract infection: a statewide analysis. Ann Intern Med 2012;157:305-312.

54. Jain M, Miller L, Belt D, King D, Berwick DM. Decline in ICU adverse events, nosocomial infections and cost through a quality improvement initiative focusing on teamwork and culture change. Qual Saf Health Care 2006;15:235-239.

55. Elpern EH, Killeen K, Ketchem A, Wiley A, Patel G, Lateef O. Reducing use of indwelling urinary catheters and associated urinary tract infections. Am J Crit Care 2009;18:535-541.

56. Apisarnthanarak A, Thongphubeth $K$, Sirinvaravong $S$, et al. Effectiveness of multifaceted hospitalwide quality improvement programs featuring an intervention to remove unnecessary urinary catheters at a tertiary care center in Thailand. Infect Control Hosp Epidemiol 2012;28:791-798.

57. Reilly L, Sullivan P, Ninni S, Fochesto D, Williams K, Fetherman B. Reducing foley catheter device days in an intensive care unit: using the evidence to change practice. $A A C N$ Adv Crit Care 2006;17:272-283.

58. Wenger JE. Cultivating quality: reducing rates of catheterassociated urinary tract infection. Am J Nurs 2010;110:40-45.

59. Rothfeld AF, Stickley A. A program to limit urinary catheter use in an acute care hospital. Am J Infect Control 2010;38:568-571.

60. Dumigan DG, Kohan CA, Reed CR, Jekel JF, Fikrig MK. Utilizing national nosocomial infection surveillance system date to improve urinary tract infection rates in three intensive-care units. Clin Perform Qual Health Care 1998;6(4):172-178.

61. Rhodes N, McVay T, Harrington L, Luquire R, Winter M, Helms B. Eliminating catheter-associated urinary tract infections, part II: limit duration of catheter use. J Healthc Qual 2009;31:13-17.
62. van den Broek P, Wille JC, van Benthem BHB, Prenboom RJM, van den Akker-van Marle ME, Niel-Weise BS. Urethral catheters: can we reduce use? BMC Urol 2011;11:10-16.

63. Oman KS, Flynn Makic MB, Fink R, et al. Nurse-directed interventions to reduce catheter-associated urinary tract infections. Am J Infect Control 2012;40:448-553.

64. Huang WC, Wann SR, Lir SL, et al. Catheter-associated urinary tract infections in intensive care units can be reduced by prompting physicians to remove unnecessary catheters. Infect Control Hosp Epidemiol 2004;25:974-978.

65. Fakih MG, Dueweke C, Meisner S, et al. Effect of nurse-led multidisciplinary rounds on reducing the unnecessary use of urinary catheterization in hospitalized patients. Infect Control Hosp Epidemiol 2008;29:815-819.

66. Venkatram S, Rachmale S, Kanna B. Study of device use adjusted rates in health care-associated infections after implementation of "bundles" in a closed-model medical intensive care unit. $J$ Crit Care 2010;25:174-181.

67. Rosenthal VD, Todi SK, Alvarez-Moreno C, et al. Impact of a multidimensional infection control strategy on catheter associated urinary infection rates in the adult intensive care units of 15 developing countries: findings of the International Nosocomial Infection Control Consortium. Infection 2012;40:517-526.

68. Goetz AM, Kedzuf S, Wagener M, Muder RR. Feedback to nursing staff as an intervention to reduce catheter-associated urinary tract infections. Am J Infect Contol 1999;7:402-404.

69. Winter M, Helms B, Harrington L, Luquire R, McVay T, Rhodes N. Eliminating catheter-associated urinary tract infections, part I: avoid catheter use. J Healthc Qual 2009;31:8-12.

70. Miller RS, Norris PR, Jenkins JM, et al. Systems initiatives reduce healthcare-associated infections: a study of 22,928 device days in a single trauma unit. $J$ Trauma 2010;68:23-31.

71. Topal J, Conkdin S, Camp K, et al. Prevention of nosocomial catheter-associated urinary tract infections through computerized feedback to physicians and a nurse-directed protocol. Am J Med Qual 2005;20:121-126.

72. Misset B, Timsit JF, Dumay MF, et al. A continuous qualityimprovement program reduces nosocomial infection rates in the ICU. Intensive Care Med 2004;30:395-400.

73. Crouzet J, Bertrand X, Venier AG, Badoz M, Husson C, Talon D. Control of the duration of urinary catheterization: impact on catheter-associated urinary tract infection. J Hosp Infect 2007; 67:253-257.

74. Jaggi N, Sissodia P. Multimodal supervision programme to reduce catheter associated urinary tract infections and its analysis to enable focus on labour and cost effective infection control measures in a tertiary care hospital in India. J Clin Diag Res 2012;6:1372-1376.

75. Loeb M, Hunt D, O'Halloran K, Carusone SC, Dafoe N, Walter $\mathrm{SD}$. Stop orders to reduce inappropriate urinary catheterization in hospitalized patients: a randomized controlled trial. $J \mathrm{Gen}$ Intern Med 2008;23:816-820.

76. Guyatt $\mathrm{GH}$, Oxman AD, Vist GE, et al. GRADE: an emerging consensus on rating quality of evidence and strength of recommendations. BMJ 2008;336(7650):924-926.

77. GRADE. Canadian Task Force on Preventive Health Care website. http://canadiantaskforce.ca/methods/grade/. Accessed December 31, 2013.

78. Saint S, Kaufman SR, Thompson M, Rogers MA, Chenoweth CE. A reminder reduces urinary catheterization in hospitalized patients. It Comm J Qual Patient Saf 2005;31(8):455-462. 